Turk J Cardiovasc Nurs 2020;11(24):31-36

Derleme Review

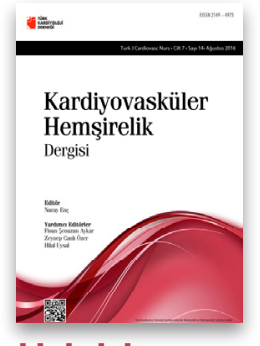

khd.tkd.org.tr

\title{
Akut Koroner Sendromlu Hastalarda Sağlıklı Yaşam Davranışlarının Kazandırılması
}

\author{
(D) Aynur Kaynar Şimşek, (1) Şule Ecevit Alpar \\ Marmara Üniversitesi Sağlık Bilimleri Fakültesi, Hemşirelik Esasları Anabilim Dalı, İstanbul
}

\begin{abstract}
Özet
Kardiyovasküler hastalıklar gelişmiş ve gelişmekte olan ülkelerde ölüm nedenleri arasında birinci sırada yer almaktadır. Bu hastalıklar arasında akut koroner sendrom (AKS) morbidite ve mortalitesi en yüksek olanıdır. Risk faktörleri kontrol altına alındığında morbidite ve mortalitesi düşürülebilen bir durum olan AKS'nin sağaltımı ve risk kontrolü ne yazık ki istendik düzeyde değildir. Bu makale akut koroner sendrom geçiren hastaların risk faktörlerini kontrol altına almak ve hastalara sağlıklı yaşam davranışları kazandırmak amacıyla yapılacak girişimler hakkında bilgi vermek amacıyla yazıldı. Anahtar sözcükler: Egzersiz; ilaç kullanımı; sağlıklı beslenme; sigara kullanımı.
\end{abstract}

\section{Obtaining of Healthy Life Behaviors in Patients with Acute Coronary Syndrome}

\begin{abstract}
Cardiovascular diseases take the first place among the reasons of death both in the developed and developing countries. Acute coronary syndrome (ACS) has the highest mortality among these diseases. Mortality and morbidity of ACS can be decreased when the known risk factors of it are controlled, however the risk control and treatment of it are not at the desired level yet. This review was written both to control the risk factors of patients with acute coronary syndrome and to generate information about the interventions performed in order to maintain healthy life habbits to the patient.

Keywords: Drug use; exercise; healthy nutrition; smoking.

Cite this article as: Kaynar Şimşek A, Ecevit Alpar Ş. Obtaining of Healthy Life Behaviors in Patients with Acute Coronary Syndrome. Turk J Cardiovasc Nurs 2020;11(24):31-36.
\end{abstract}

$\mathrm{K}^{\mathrm{a}}$ ardiyovasküler hastalıklar gelişmiş ve gelişmekte olan ülkelerde ölüm nedenleri arasında birinci sırada yer almaktadır. ${ }^{[1-3]}$ Ülkemizde 2009-2016 yıllarında yaşanan ölüm olaylarının epidemiyolojik yönden incelendiği bir çalışmada, tüm yıllarda ölüm nedenlerinin birinci sırasında kardiyovasküler hastalıkların yer aldığı bildirilmiştir. ${ }^{[4]}$ Kardiyovasküler hastalıkların içerisinde ise iskemik kalp hastalıklarına bağlı ölümler birinci sırada yer almaktadır. ${ }^{[5]}$ |̇ske- mik kalp hastalıklarından biri olan akut koroner sendrom (AKS), ani miyokard iskemisi sonucu ortaya çıkan ciddi bir tablodur. ${ }^{[6-9]}$ AKS'nin mortalite oranı yaklaşık \%30'dur ve bu oran diğer ölüm oranlarıyla karşılaştırıldığında oldukça yüksek bir değerdir. ${ }^{[10]}$ AKS'de ikincil korunma yöntemleri mortaliteyi düşürme açısından çok büyük önem taşımaktadır. Medikal tedaviye ek olarak hastada yaşam tarzı değişikliğinin sağlanması önerilmektedir. ${ }^{[11,12]}$ 
EUROASPIRE-IV (2012-2013) ve EUROASPIRE-III (2006-2007) (European Action on Secondary and Primary Prevention by Intervention to Reduce Events) çalışmasında, Türkiye'nin de 17 merkez ile dahil olduğu 24 Avrupa ülkesinde (78 merkezde), koroner arter hastalığı (KAH) olan kişilerde yaşam tarzı, risk faktörlerinin değişimi ve ilaç tedavileri araştırılmıştır. EUROASPIRE-IV verileri ile EUROASPIRE-III verileri karşılaştırıldığında Türkiye kolunda sigara içme oranı \%23.1'den $\% 25.5$ 'e ( $p=0.499)$, obezite \%35.5'ten \%40.7'ye $(p=0.211)$, total kolesterol yüksekliği \%48.3'ten $\% 49.6$ 'ya $(p=0.767)$ ve diyabet \%33.6'dan \%39.7'ye ( $p=0.139)$ yükselmiştir. EUROASPIRE IV çalışmasıyla; Türkiye kolunda koroner arter hastalarında ikincil korumanın yeterli düzeyde olmadığı, hatta altı yıl öncesine göre olumsuz yönde ilerlediği, genel Avrupa ortalamasına göre bazı risk faktörlerinin daha kontrolsüz olduğu ve genç yaşta akut koroner sendrom gibi iskemik olayların hâlâ önemli bir sorun olduğu saptanmıştır. ${ }^{[13]}$ Sonuç olarak risk faktörleri kontrol altına alındığında mortalitesi düşürülebilen bir durum olan AKS'nin sağaltımı ve risk kontrolü ne yazık ki istendik düzeyde değildir.

Bu makale akut koroner sendrom geçiren hastaların risk faktörlerini kontrol altına almak ve hastalarda sağlıklı yaşam davranışları kazandırmak amacıyla yapılacak girişimler hakkında bilgi vermek amacıyla yazıldı.

\section{Risk Faktörleri}

Kardiyovasküler hastalıklarla ilişkili olan risk faktörleri; sigara kullanımı, yüksek kan basıncı, diabetes mellitus, dislipidemi, yetersiz fiziksel aktivite ve obezite olarak bildirilmiştir. ${ }^{[10,14,15]}$ Risk faktörlerinin kontrol altına alınması AKS geçiren bireylerin yaşam süresini ve sağlık düzeyini artırmada önemi tartışılmazdır. Avrupa klinik uygulamada kardiyovasküler hastalıklardan korunma kılavuzunda (versiyon 2016) (European Society of Cardiology), kardiyovasküler hastalık tanısı alan bireyler için hedefler belirlenmiştir. ${ }^{[16]}$

Bu hedefler;

- Sigara içenlerin sigarayı bırakmaları,

- Düzenli fiziksel aktivite yapmaları,

- Bireylerin beden kitle indeksinin (BKi) $25 \mathrm{~kg} / \mathrm{m}^{2}$, bel çevresinin erkeklerde $94 \mathrm{~cm}$; Kadınlarda $80 \mathrm{~cm}$ altında olması,

- Kan basıncının 140/90 mmHg altında olması,

- Total kolesterol plazma seviyesinin $175 \mathrm{mg} / \mathrm{dl}$, düşük dansiteli lipoprotein (LDL) plazma seviyesinin 100 mg/ dl altına olması,

- Diabetes mellitus tanısı olan bireylerde: Açlık kan şekerinin $125 \mathrm{mg} / \mathrm{dl}$, gilikolize hemoglobin (HbA1c) seviyesinin \%6.5 altında olması şeklindedir.

\section{Sağlıklı Yaşam Davranışlarının Kazandırılması}

Avrupa Klinik Uygulamada Kardiyovasküler Hastalıklardan Korunma Kılavuzu'unda belirtilen hedeflere ulaşılmasında yaşam tarzı değişikliklerinin yapılması en önemli basamaklardan biridir. ${ }^{[17,18]}$ Çünkü kardiyovasküler hastalıklar çok boyutludur ve birçok faktörden etkilenmektedir. ${ }^{[19]}$ Yaşam tarzı değişikliği olmadan medikal tedavinin hedeflere ulaşmada etkisiz kaldığı bildirilmiştir. ${ }^{[17,18]}$ Bu nedenle bireyler mutlaka sağlıklı yaşam davranışları konusunda bilgilendirilmelidir. ${ }^{[20]}$ Sağlıklı yaşam davranışlarının kazandırıması, risk faktörlerinin doğru yönetimi ve ilaçların doğru kullanımı kardiyovasküler olaylardan korumanın temel prensipleridir. ${ }^{[16]}$

\section{Sağlıklı Beslenme}

Sağlıklı ve dengeli beslenmeyle birlikte; kan şekeri, kan basıncı ve plazma lipit düzeyi kontrol altına alınabilir. [21]

Hastalara sağlıklı beslenmeye yönelik verilecek tavsiyeler;

- Toplam yağ tüketiminden ziyade tüketilen yağların tipi önemlidir. Doymuş yağ tüketimi en aza indirin. Doymuş yağlar yerine doymamış yağları (fındık, ceviz, zeytinyağı gibi) tercih edin. ${ }^{[16,21]}$ Doymuş yağlardan alınan enerji toplam enerjinin $<\% 10$ 'unu oluşturmalıdır, diyetinizde yağ kısıtlamasına gidin. ${ }^{[16,22]}$

- Trans yağ asitleri tüketimi en aza indirin. Tercihen işlenmiş gıdaları hiç tüketmeyin. Doğal kaynaklardan alınan trans yağlar ise toplam enerjinin sadece $<\% 1$ 'ini oluşturmalıdır, trans yağ tüketimini en aza indirin. [16]

- Kolesterolün diyette üst sınırı yoktur ama 'haftada 1-2 kez 1 yumurta (tercihen haşlama ya da sebze yemeklerinin içinde) sağlıkıı bir diyetin parçası olabilir' aşırı kolesterol alımından kaçının. ${ }^{[22]}$

- Karbonhidrat tüketimini en aza indirin. En fazla günlük kalorinin \%10'u kadar karbonhidrat alınmalıdır. ${ }^{[22]}$

- Paketlenmiş gıdaları tüketmekten kaçının ve paketlenmiş gıdalar alırken üzerindeki etiketleri okuyun. Tuz, trans yağ, doymuş yağ ve şeker eklenmiş gıdaları tercih etmeyin. ${ }^{[16,22]}$

- Kırmızı et tüketimi haftada bir kez bir el ayası kadar et ya da 3-4 köfte ile sınırlandırın. Kırmızı etin doymuş yağ ve kolesterol içeriği beyaz ete göre daha yüksektir. Yağlı kırmızı et yerine, yağsız kırmızı et veya derisiz tavuk, hindi eti ya da balıketini tercih edin. ${ }^{[22]}$

- Yüksek omega-3 yağ asidi içeriği nedeniyle balığı haftada en az 1-2 kez ızgara, fırın veya buğulama şeklinde tüketin. ${ }^{[16]}$

- Normal kiloda bireyler tam tahıl (tam buğday ekme- 
ği, esmer pirinç, tam tahıllı gevrekler, tam tahıl unları) grubundan günde 4-6 porsiyon tüketebilir (tam tahılIı ekmek: 2 ince dilim 1 porsiyon; tam tahıllı makarna, bulgur vb.: 4-5 yemek kaşığı 1 porsiyon). İşlenmiş rafine tahılların tüketimini (pirinç, un ve unlu mamuller) en aza indirin. ${ }^{[23]}$

- Günlük meyve ve sebze tüketimi kalp damar sağlığı için önemlidir. Günde $200 \mathrm{gr}$ meyve (2-3 adet meyve), $200 \mathrm{gr}$ (2-3 porsiyon) sebze tüketin. ${ }^{[16,23]}$

- Alkollü içecekleri, erkeklerde günde 2 bardak (20 gr/gün), kadınlarda bir bardak (10 gr/gün) ile sınırlı tutun. ${ }^{[16,23]}$

- Tuz tüketiminizi $5 \mathrm{gr} / g u ̈ n ' d e n$ az olacak şekilde sınırlandırın. ${ }^{[16,22,24]}$

\section{Tuz tüketimini azaltmaya yönelik hastalara verilecek öneriler; $[16,22,24]$}

- Daima taze ve tuz eklenmemiş besinleri tercih edin,

- Sofrada tuzluk kullanmayın,

- Yemeklerin tadına bakmadan tuz kullanma alışkanlığından vazgeçin,

- Maydanoz, nane, kekik, dere otu, rezene, fesleğen gibi aroma sağlayıcıları tuz yerine tercih edin,

- Turşu, ketçap, hardal, soya sosu, hazır salata sosları vb. yiyeceklerin tuz içeriği yüksektir, bu besinlerden uzak durun.

\section{Fiziksel Aktivite}

Fiziksel aktivite ve egzersiz mutlaka kontrollü ve bilinçli bir şekilde yapılmalıdır. Kardiyovasküler hastalık tanısı olan bireyler orta yoğunlukta egzersiz yapmaları için yönlendirilmelidir. Nabız kontrolü yapmak ya da yürü konuş testi aktivite seviyesini ayarlama da önemlidir. Yürü konuş testi, egzersiz şiddetini belirlemede kullanılan yardımcı bir yöntemdir. Kişinin egzersiz sırasında (ör; tempolu yürüyüş) konuşabildiği, ancak şarkı söyleyemediği tempo orta yoğunlukta kabul edilir. ${ }^{[25]}$ Fiziksel aktivite/egzersiz örnekleri sadece doğa yürüyüşü yapmak, koşmak, paten kaymak, bisiklet sürmek, kürek çekmek, yüzmek, aerobik dersi gibi sporla ilişkili aktiviteleri değil, aynı zamanda tempolu yürüme, merdiven çıkma, daha fazla ev ve bahçe işleri yapma ve aktif yaratıcı faaliyetlere katılma gibi yaşam tarzıyla ilgili aktiviteleri de kapsar. ${ }^{[16]}$ Sedanter hastalar, uygun şekilde egzersiz ile ilgili risk değerlendirmesi yapıldıktan sonra, egzersiz programlarına başlamaları için kuvvetle teşvik edilmelidir. ${ }^{[26-28]}$ Düzenli ve Kontrollü Fiziksel Aktivitenin Yararları; [29, 30]

- Kolleteral damarların sayısını artırır. Böylece kalbin kanlanması artar, miyokart infarktüsü geçirme riski azalır,
- Arterlerin çapında genişleme sağlayarak kan basıncının düşmesine yardımcı olur,

- Vücudun hareket ve egzersiz kapasitesinde artışsağlar,

- Plazma hacminde artış, kan viskozitesinde azalma, trombosit agregasyonunda azalma ve trombolitik kapasitede iyileşme gibi, antitrombotik etkileri olup koroner tıkanma riskini azaltır. ${ }^{[31]}$

Öyküsünde akut miyokart infarktüsü, koroner arter bypass grefti, perkütan koroner girişimi, kararlı anjina pektoris veya kronik kalp yetersizliği olan hastalara egzersiz kapasitesini artırmaya yönelik verilecek tavsiyeler; ${ }^{[27,28,32]}$

- Fiziksel aktiviteyi/egzersizi mutlaka kontrollü ve bilinçli bir şekilde yapın. Kontrolsüz olarak ağır aktivite yapmayın.

- Egzersiz yapmaya düşük tempodan başlanıp yavaş yavaş tempo ve süresini artıın,

- Haftada en az 3 kez ve seans başına 30-45 dakika orta yoğunlukta egzersiz yapın,

- Egzersiz sırasında yürü konuş testini yaparak doğru yoğunlukta egzersiz yapın,

- Günlük işler sırasında da aktif olduğunuz zamanı artırın (ör: asansör değil merdiven kullanın, arabayı uzağa park edip eve yürüyün vb.).

\section{Sağlıklı Vücut Ağırlığının Korunması}

Kilo fazlalığı ve obezite yüksek mortaliteyle ilişkilidir. ${ }^{[33]}$ Beden kitle indeksinin $>25 \mathrm{~kg} / \mathrm{m}^{2}$ olması ve kadınlarda bel çevresinin $>80 \mathrm{~cm}$, erkeklerde bel çevresinin $>94 \mathrm{~cm}$ olması kardiyak açıdan risk faktörü olarak kabul edilmektedir. ${ }^{[15,}$ $16,23]$ Vücut ağırlığının korunmasına yönelik hastalara verilecek öneriler; [23]

- Paketlenmiş gıdaları tüketmeyin,

- Tuzlu ve yağlı çerez türlerini tüketmeyin,

- Hafta da bir kez aynı saatte ve aynı kıyafetlerle kilo kontrolü yapın,

- Eğer beden kitle indeksiniz veya bel çevreniz hedef değerin üzerinde ise kilo vermek için sağlık profesyonellerinden öneriler alın.

\section{Sigaranın Bırakılması}

Tütün ve tütün ürünleri kullanımına bağlı olarak 20'nci yüzyılda 100 milyon kişi hayatını kaybetmiştir. Tütün kullanımı engellenemezse 21 'inci yüzyılda tütüne bağlı nedenlerden 1 milyar kişinin hayatını kaybetmesi beklenmektedir. ${ }^{[34]}$ Sigara çok sayıda hastalığın kanıtlanmış nedenidir. Sigara kronik kalp yetersizliği, iskemik olaylar, inme, pulmoner 
arter hipertansiyonu ve abdominal aort anevrizması gibi birçok kardiyovasküler hastalık riskiyle ilişkilidir. Hem farmakolojik hem de psikolojik olarak güçlü bir bağımlılık yarattığı için sigarayı bırakmak karmaşık ve zorlu bir süreçtir. Sigarayı bırakmada başarının en önemli faktörü motivasyondur ve motivasyon profesyonel yardımla yükseltilebilir. Günlük uygulama da sigarayı bıraktırma stratejisi (5A); [16]

A (Ask) - Sorun: Her firsatta sigara içme durumunu sistematik olarak araştırın.

A (Advise) - Tavsiye: Tüm sigara içenleri tartışmasız bırakmaya çağırın.

A (Assess) - Değerlendirme: Kişinin bağımlılık ve bırakmaya hazır olma derecesini belirleyin

A (Assist) - Yardım: Bırakma tarihi, davranışsal danışmanlık ve farmakolojik destek dahil sigarayı bırakma stratejisi üzerinde anlaşın.

A (Arrange)- Düzenleme: Bir takip programı düzenleyin.

Sigarayı bırakmaya yönelik hastalara verilecek tavsiyeler; ${ }^{[35]}$

- Sigaradan alınan keyif ve haz fizyolojik bir intiyacın karşılanmasından alınan keyif ve haz ile eşdeğerde olmayıp bir şartlanmadır. Güçlü bir irade kontrolü ve kararlııı ile durumu tersine çevirmenin de insanoğluna özgü olduğu düşüncesi ile bu zararlı alışkanlık ile çok geç olmadan yollarınızı ayırın.

- Hemen bırakamıyorsanız bir tarih belirleyin ve o tarihte kesinlikle sigarayı bırakın,

- Sigarayı bırakmada tek başınıza başarılı olamayacağınızı düşünüyorsanız mutlaka tıbbi destek alın.

\section{İlaçların Kullanılması}

İlaçların kullanılması konusunda hastalar bilgilendirilmelidir. Taburculuk esnasında hastanın kullanacağı ilaçlar ve bu ilaçların alınması gereken zamanları gösteren çizelgelerin hastalara verilmesi önerilmektedir. ${ }^{[23]}$ îlaç kullanım uyumunu artırmaya yönelik öneriler;

- Tedavinin yararı ve olası yan etkileri, kullanım zamanı ve süresi konusunda net öneriler verin,

- Hastanın alışkanlıklarını ve tercihleri dikkate alın,

- Hastalara, tedavi konusunda düşüncelerini sorun, sorunlar ve olası çözümleri tartışın,

- Tekrarlayan izlemler yaparak uyumu değerlendirin,

- Israrlı ilaç uyumsuzluğu durumunda, çok oturumlu eğitimsel faaliyetler düzenleyin, ${ }^{[16]}$

İlaçların kullanılmasına Yönelik Hatalara verilecek öneriler; ${ }^{[23]}$

- Hekiminizin önerdiği ilaç tedavisine kesin olarak uyun,
- İlaç tedavisinde, ilaçlarınızın isimlerini, dozlarını, hangi amaçla kullandığını, yan etkilerini, acil durumlarda kullanmanız gereken ilaçları, besin ya da ilaç etkileşimlerini ve ilaçların kullanma zamanlarını öğrenin,

- Hekim önerisi olmadan asla ilaçlarınızı almayı bırakmayın.

\section{Stres Yönetimi}

Düşük sosyoekonomik düzey, sosyal destek eksikliği, depresyon, anksiyete, düşmanlık ve $D$ tipi kişilik hem kardiyovasküler hastalık gelişme riskine, hem de kardiyovasküler hastalığın klinik seyrinin ve prognozunun kötüleşmesine katkıda bulunur. ${ }^{[16]}$ Kardiyovasküler hastalığı olan bireylerde stres düzeyinin yüksek olduğu[36] ve özellikle 50 yaş üzerini bireylerde riski daha da arttırdığı bildirilmiştir. ${ }^{[37]}$ Stres hem tedaviye uyumu, hem yaşam tarzı değişikliği çabalarını, hem de hasta ve toplumlarda sağlık ve refah düzeyinin yükselmesini olumsuz etkiler. Bu nedenle bireylerin stres düzeyi klinik görüşme veya standart anketlerle değerlendirilmelidir. ${ }^{[16]}$ Günlük yaşamda stresin tamamen ortadan kaldırıması mümkün değildir. Bireyler stresin olumsuz etkilerinden korunmak için, stresi yönetebilmeli ve stres ile baş etmeyi öğrenmelidir. Stres yönetimi, strese uyum veya stresle başa çıkabilme becerisinin geliştirilmesi ile sağlanmaktadır. ${ }^{[38]}$

Stresle baş etmede hastaya verilecek öneriler;

- Eğer mümkünse size stres yaratan ortamı ve koşulu değiştirin,

- Stres yaratan faktörlerden uzak durun,

- Hayatınızdaki olayları kontrol edememe duygusu sizi strese sokabilir. Bu durumdan kurtulmanın en kolay yolu kendi yaşamınızı kontrol altına almaktır. Önemli kararlar alın ve bu kararlara uyun,

- Değiştiremediğiniz, gücünüzü aşan olayların pozitif yönlerini bularak kabul edin,

- Gevşeme egzersizleri, sosyal, kültürel ve sportif etkinliklere katılma, masaj, dua ve ibadet, zaman yönetimi gibi teknikler stres yönetiminde etkili olabilir. Kendinize en uygun yöntemi seçin ve uygulayın,

- Sosyal destek alabileceğiniz bir yakınınız/yakınlarınız varsa sosyal destek alın.

\section{Sonuç}

Sonuç olarak AKS ani kalp ölümüyle sonuçlanabilmesi nedeniyle oldukça riskli ve ciddi bir tablodur. ${ }^{[22]}$ Sağlık profesyonellerinin üzerine düşen en önemli görevlerin biri hastanın ihtiyaç duyduğu bilgiyi karşılanmaktır. ${ }^{[39]} \mathrm{Bu}$ amaçla hastaların akut dönemi atlatmalarını takiben yaşam tarzı 
değişikliği konusunda bilgilendirilmesi, eğitimler düzenlenerek farkındalıklarının artııılması ve sağlıklı yaşam davranışlarına yönlendirilmesi hayat kurtarıcıdır. ${ }^{[20]}$

\section{Bu makale doktora tezinden üretilmiştir.}

Hakem Değerlendirmesi: Dış bağımsız.

Çıkar Çatışması: Yazarlar arasında herhangi bir çıkar çatışması bulunmamaktadır.

Yazarlık Katkıları: Konsept: A.K.Ş., Ş.E.A.; Dizayn: A.K.Ş., Ş.E.A.; Veri Toplama veya İşleme: A.K.Ş.; Literatür Arama: A.K.Ş.; Yazan: A.K.Ş.

\section{Kaynaklar}

1. Buğan B, Çelik T. Koroner Arter Hastalığı Risk Faktörleri. J Clin Anal Med 2014;5:159-163. [CrossRef]

2. Kurçer MA, Özbay A. Koroner Arter Hastalarında Uygulanan Yaşam Tarzı Eğitim ve Danışmanlığının Yaşam Kalitesine Etkisi. Anadolu Kardiyoloji Dergisi 2011;1:107-113.

3. Oğuz S, Erguvan B, Ünal G, Bayrak B, Çamcı G. Üniversite Öğrencilerinde Kardiyovasküler Hastalıklar Risk Faktörleri Bilgi Düzeyinin Belirlenmesi. MN Kardiyoloji 2019;26:184-191.

4. Emik KY, Önal AE. 2009-2016 Yıllarında Türkiye'deki Ölümlerin Epidemiyolojik Yönden İncelenmesi Ve Ölüm Bildirim Sisteminin Önemi. İstanbul Tıp Fakültesi Dergisi 2019;82:149-155.

5. Bayrak B, Oğuz S, Arslan S, Candar B, Keleş S, Karagöz B, et al. Miyokard İnfarktüsü Geçirmiş Hastalarda Algılanan Stresin Belirlenmesi. Turk J Cardiovasc Nurs 2019;10:129-137. [CrossRef]

6. Aydınalp A, Müderrisoğlu H. Akut Koroner Sendrom. In: Akut koroner Sendromun Tanımı ve Gelişimi. 1st ed. Ankara: Hacettepe Üniversitesi Hastaneleri Basım Evi; 2009. p. 1-10.

7. Meriç M. ST yükselmesi olmayan akut koroner sendromlar. Journal of Experimental and Clinical Medicine 2012;29:133-139.

8. Steg PG, Ducrocq G. Future of the Prevention and Treatment of Coronary Artery Disease. Circ J 2016;80:1067-1072. [CrossRef]

9. Yağlı VN, Ince Di, Sağlam M, Çalık Kütükçü E, Arıkan H. Akut Koroner Sendromlu Hastalarda Anksiyete Ve Depresyonu Belirleyen Faktörler. Turk J Physiother Rehabil 2015;26:40-46.

10. Singh N, Rathore V, Mahat RK, Rastogi P. Glycogen Phosphorylase BB: A more Sensitive and Specific Marker than Other Cardiac Markers for Early Diagnosis of Acute Myocardial Infarction. Indian J Clin Biochem 2018;33:356-360. [CrossRef]

11. Hamm CW, Bassand JP, Agewall S, Bax J, Boersma E, Bueno H, et al. Avrupa Kardiyoloji Cemiyeti'nin (ESC) Israrcı ST-segment yükselmesi belirtileri göstermeyen hastalarda Akut Koroner Sendromların (AKS) tedavi kılavuzları. Türk Kardiyol Dern Arş 2011;3:73-128.

12. James $S K$, Atar $D$, Badano LP, Lundqvist $C B$, Borger MA, Di Mario $C$, et al. ST-segment Yükselmeli Akut Miyokart Enfarktüsü ile Başvuran Hastaların Tedavisine İlişkin ESC Kılavuzu. Türk Kardiyol Dern Arş 2013;3:1-51.

13. Tokgözoğlu L, Kayıkçıoğlu M, Altay $S$, Aydoğdu S, Barçın Bos$\tan$ C, Çakmak HA, et al. EUROASPIRE-IV: Avrupa Kardiyoloji Derneği'nin koroner arter hastalarında yaşam tarzı, risk faktör- leri ve tedavi yaklaşımı üzerine çalışması: Türkiye verileri. Turk Kardiyol Dern Ars 2017;45:134-144.

14. Madhavan MV, Gersh BJ, Alexander KP, Granger CB, Stone GW. Coronary Artery Disease in Patients $\geq 80$ Years of Age. J Am Coll Cardiol 2018;71:2015-2040. [CrossRef]

15. Onat A, Can G, Yüksel H, Ademoğlu E, Ünaltuna NE, Kaya A, et al. TEKHARF 2017 Tıp Dünyasının Kronik Hastalıklara Yaklaşımına Öncülük. Logos Yayıncılık Tic. A.Ş; 2017. p. 1-294.

16. Piepoli MF, Hoes AW, Agewall S, Albus C, Brotons C, Catapano AL, et al. 2016 European Guidelines on cardiovascular disease prevention in clinical practice: The Sixth Joint Task Force of the European Society of Cardiology and Other Societies on Cardiovascular Disease Prevention in Clinical Practice (constituted by representatives of 10 societies and by invited experts) Developed with the special contribution of the European Association for Cardiovascular Prevention \& Rehabilitation (EACPR). Atherosclerosis 2016;252:207-274. [CrossRef]

17. Auer R, Gaume J, Rodondi N, Cornuz J, Ghali WA. Efficacy of in-hospital multidimensional interventions of secondary prevention after acute coronary syndrome: a systematic review and meta-analysis. Circulation 2008;117:3109-3117. [CrossRef]

18. Chow CK, Jolly S, Rao-Melacini P, Fox KA, Anand SS, Yusuf $S$. Association of diet, exercise, and smoking modification with risk of early cardiovascular events after acute coronary syndromes. Circulation 2010;121:750-758. [CrossRef]

19. Bayrak B, Oğuz S, Karabulut Z, Çelik S, Kodak C. Kalp Yetersizliği Hastalarında Ölüm Kaygısının Belirlenmesi. Turk J Cardiovasc Nurs 2019;10:97-104. [CrossRef]

20. Kalyoncuoğlu M, Öztürk S, Durmuş G, Keskin B, Can MM. Güncel Tedavi Kılavuzları Işığında Kronik İskemik Kalp Hastalığı Tedavisine Yaklaşım. Med Bull Haseki 2017;55:85-100. [CrossRef]

21. Bhupathiraju SN, Tucker KL. Coronary heart disease prevention: nutrients, foods, and dietary patterns. Clin Chim Acta 2011;412:1493-1514. [CrossRef]

22. Kayıkçığlu M, Özdoğan Ö. Beslenme ve Kardiyovasküler Sağlık: 2015 Amerikan Diyet Kılavuzu Önerileri Turk Kardiyol Dern Ars 2015;43:667-672.

23. Kasapoğlu ES, Enç N. Koroner Arter Hastaları için Bir Rehber. Journal of Cardiovascular Nursing 2017;8:1-7. [CrossRef]

24. Bilici M, YıImaz F, Illhan US, Borazan A. Hastanın günlük Ne Kadar Tuz Tükettiğini Bilmesi Tuz Tüketimini Azaltır MI? Medeniyet Medical Journal 2016;31:237-240.

25. Ardıç F. Egzersiz Reçetesi. Türk Fiz Tıp Rehabilitasyon Dergisi 2014;60:1-8. [CrossRef]

26. Catapano LA, Graham I, De Backer G, Wiklund O, Chapman MJ, Drexel H, Hoes AW, et al. Dislipidemilerin Tedavisine Ilişkin 2016 ESC/EAS Kılavuzu, Türk Kardiyol Dern Arş 2017;1-72.

27. Taylor RS, Brown A, Ebrahim S, Jolliffe J, Noorani H, Rees K, et al. Exercise-based rehabilitation for patients with coronary heart disease: systematic review and meta-analysis of randomized controlled trials. Am J Med 2004;116:682-92. [CrossRef]

28. Piepoli MF, Davos C, Francis DP, Coats AJ; ExTraMATCH Collaborative. Exercise training meta-analysis of trials in patients with chronic heart failure (ExTraMATCH). BMJ. 2004;328:189. 
29. Linke A, Erbs $S$, Hambrecht R. Effects of exercise training upon endothelial function in patients with cardiovascular disease. Front Biosci 2008;13:424-432. [CrossRef]

30. Di Francescomarino S, Sciartilli A, Di Valerio V, Di Baldassarre A, Gallina $S$. The effect of physical exercise on endothelial function. Sports Med 2009;39:797-812. [CrossRef]

31. Lippi G, Maffulli N. Biological influence of physical exercise on hemostasis. Semin Thromb Hemost 2009;35:269-276. [CrossRef]

32. Saka T. Koroner Kalp Hastalığı ve Egzersiz. Spor Hekimliği Dergisi 2016;51:56-68.

33. Zheng W, McLerran DF, Rolland B, Zhang X, Inoue M, Matsuo K, et al. Association between body-mass index and risk of death in more than 1 million Asians. N Engl J Med 2011;364:719-29.

34. Çalışkan S, Metintaş S. Dünyada Tütün Kontrol Uygulamalarının Küresel Ölçekte Değerlendirilmesi. Türk Dünyası Uygula- ma ve Araştırma Merkezi Halk Sağlığı Dergisi 2018;3:32-41

35. Özcan S, Taş HY, Çetin Y. Sigara İle Mücadelede Toplumsal Bilinç. Uluslararası Emek ve Toplum Dergisi 2013;2:154-175.

36. Şimşek AK, Şimşek T, Alpar ŞE. Açık Kalp Ameliyatı Olacak Hastalara Verilen Preoperatif Eğitimin: Postoperatif Dönemde Anksiyete ve İyileşme Sürecine Etkisinin İncelenmesi. Ege Üniversitesi Hemşirelik Fakültesi Dergisi 2018;34:45-62.

37. Oğuz S, Çamcı G. Koroner Arter Hastalığı ve İş Yaşamı. Journal of Cardiovascular Nursing 2016;7:15-23. [CrossRef]

38. Sürme Y. Stres, Stresle İlişkili Hastalıklar ve Stres Yönetimi. Uluslararası Sosyal Araştırmalar Dergisi 2019;12:525-529.

39. Sevinç S. Miyokart İnfarktüsü Geçirmiş Bireylerde Yaşam Şekli Değişikliği: Pender'in Sağlığı Geliştirme Modeli. Journal of Cardiovascular Nursing 2016:7:147-152. 